\title{
Influence of biological maturation on speed, jump, and endurance in high-level youth soccer players
}

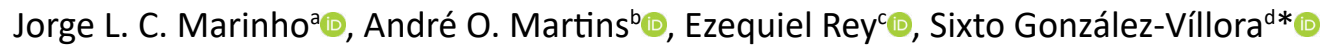

\section{Keywords:}

Youth sports;

Physical fitness;

Child development;

Adolescent development.

\section{Keywords:}

Esporte juvenil;

Aptidão física;

Desenvolvimento infantil; Desenvolvimento; Adolescente.

\begin{abstract}
The goal of this study is to identify the influence of the maturity state in the physical components of the high level youth male soccer players of an elite club in Brazil. Eighty-seven young male soccer players participated in this study, distributed in $34 \mathrm{U}-14$ players, $23 \mathrm{U}-16$ players and 30 U-19 players. Peak height velocity (PHV) was estimated: Pre-PHV (<-1.0 years, $n=13)$, mid-PHV ( -0.99 to 0.5 years, $n=41)$, and post-PHV (>0.5 years, $n=33)$. Running-based anaerobic sprint test, squat jump, yo-yo and $30 \mathrm{~m}$ speed test were performed. The results of this study suggest that the maturational development influences vertical jump. VO2max, yo-yo test distance, fatigue index and power. This information is essential for the identification and effective development of talented football players.
\end{abstract}

\section{RESUMO}

O objetivo deste estudo foi identificar a influência do estado de maturidade nos componentes físicos dos atletas juvenis masculino de alto nível de um clube de elite no Brasil. 87 jovens jogadores de futebol participaram deste estudo, 34 sub-14, 23 sub-16 e 30 sub-19. O pico de velocidade de crescimento (PVC) foi estimado como velocidade de altura pré-PVC $(<-1,0$ anos, $n=13)$, velocidade média de pico $(-0,99$ a 0,5 anos, $n=41)$ e velocidade de altura pós-PVC $(>0,5$ anos, $n=33)$. Foram realizados sprint test, salto vertical, yo-yo e velocidade de $30 \mathrm{~m}$. Os resultados sugerem que o desenvolvimento maturacional influencia salto vertical, VO2max, distância do teste de yo-yo, índice de fadiga e potência. Esta informação é essencial para a identificação e o desenvolvimento de jogadores de futebol talentosos.

\section{RESUMEN}

El objetivo de este estudio fue identificar la influencia del estado de madurez en los componentes físicos en jóvenes futbolistas varones pertenecientes a un club de élite en Brasil. 87 jóvenes jugadores de fútbol participaron en este estudio, 34 jugadores sub-14, 23 sub-16 y 30 sub-19. La velocidad máxima de crecimiento se calculó el PVC como la velocidad elevada previa al PVC (<-1.0 años, $n=13)$, velocidad elevada media ( -0.99 a 0.5 años, $n=41)$ y velocidad elevada posterior al PVC (>0.5 años, $n=33$ ). Se realizaron las siguientes pruebas: sprint test, salto vertical, yo-yo y velocidad $30 \mathrm{~m}$. El desarrollo de la maduración influye en el salto vertical, VO2max, distancia en el test yo-yo, índice de fatiga y potencia. Esta información es fundamental para la identificación y el desarrollo adecuado de los jugadores con talento futbolístico.

\footnotetext{
a Universidad Autónoma de Madrid, Departamento de Educación Física, Deporte y Motricidad Humana, Madrid, España.

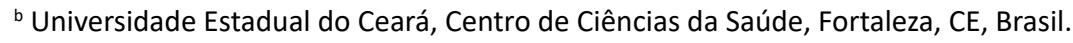

' Universidad de Vigo, Facultad de Ciencias de la Educación y del Deporte, Didácticas especiais, Pontevedra, España.

d Universidad de Castilla-La Mancha, Facultad de Educación, Cuenca, España.
}

\footnotetext{
* Autor correspondente: Sixto González-Víllora

E-mail: sixto.gonzalez@uclm.es
} 


\section{INTRODUCTION}

Soccer is the most popular sport in the world, having several factors that attract young people to practice it. However, the model of selection of talents in soccer that is adopted by clubs or schools presents diversified criteria, without standardization, using empirical methods and straying from the theoretical principles (Johnson et al., 2017). Besides, the biological age is often misleading, resulting in the loss of many talents just because of delays in the maturing process (Malina et al. 2015). In addition, players with the same age in birth years share the same initial soccer categories so that players in different stages of maturity compete with each other.

The biological maturity plays an important role in the somatic development and in the effect on the other variables that involve sport training, regarding the population of young footballers (Vandendriessche et al., 2012; Meylan et al., 2014; Malina \& Rogol, 2011). The process of biological maturity provides methods of measurement and classification by applying different biological indicators, among which the somatic indicator is highlighted (Malina et al., 2012); Johnson et al., 2017).

The somatic indicator is based on the Peak height velocity (PHV), and it was proposed by (Mirwald et al., 2002). This indicator consists in the measurement of the anthropometric variables such as height, trunk-cephalic height, length of the lower limbs, and total body mass; based on these measurements, an equation calculates the decimal values relative to the distance that the young person is from the moment of the PHV occurrence. These values can be negative so that the PHV will still occur, or positive so that the PHV has occurred (Malina et al., 2012; Mirwald et al., 2002). The evaluation of the biological maturity is important to verify the speed of the maturity, which can be early, normal, or late (Malina, 1988).

The PHV-somatic maturity has many advantages with respect to the presented methodologies, since it is a non-invasive technique, easy to apply, cheap, wellaccepted by the scientific community, and it can be applied in a transversal way (Malina, 1988).

The PHV allows for obtaining an indicator of morphological age, representing a great advantage, by providing a valid and reliable element that guides the coaches to identify the level of maturity of the player: early, average, or late. Likewise, it can help design training programs and competition that are appropriate for the individual training capacity of each player to obtain an optimal preparation (Malina et al., 2012). Therefore, the objective of this work was to identify the influence of the maturity state on the physical components of the young soccer players of an elite club in Brazil.

\section{MATERIALS AND METHODS}

\section{Participants}

Eighty-seven young male soccer players from a Brazilian club were invited to participate in the study. The following inclusion criteria were adopted: (1) participation in systematic training in soccer for at least one year; (2) participation in official regional competitions; and (3) free and clarified consent term signed by parent or guardian.

The sample was non-probabilistic and was obtained from the young soccer players between 13 and 19 years (U-14, U-16 and U-19 categories aged), obtaining a total of 87 participants from that club, distributed in $34 \mathrm{U}-14$ players ( $13.67 \pm 0.43$ years), $23 \mathrm{U}-16$ players (15.43 \pm 0.49 years) and $30 \mathrm{U}-19$ players (17.86 \pm 0.63 years). The data collection was performed during two days, with an interval of four days between the two sessions.

The experimental protocol was conducted in accordance with the Declaration of Helsinki and the study protocol was approved by the Universidad Autónama de Madrid's Ethics Committee.

\section{Procedures}

\section{MATURITY STATE}

Standard procedures were used for anthropometric measurements. The PHV protocol has been successfully validated against the gold standard (i.e. hand-wrist $\mathrm{X}$-rays, correlation coefficient of 0.83 ; (Mirwald et al., 2002): $\mathrm{PHV}=-9,236+(0,0002708 \times$ (leg length $\times$ setting height $))+(-0,001663 \times(C A \times$ leg length $))+(0,007216$ $x(C A \times$ setting height $))+(0,02292 \times$ ((body mass $/$ stature) $x$ 100).Participants were further divided into 3 maturity groups based on biological age: Pre-PHV $(<-1.0$ years, $n=13)$, Mid-PHV ( -0.99 to 0.5 years, $n=41)$, and Post-PHV ( $>0.5$ years, $n=33$ ) groups for analysis (Meylan et al., 2014).

\section{Physical performance}

Before testing, all participants performed $10 \mathrm{~min}$ of standardized warm-up comprising 2 minute of light active static stretching (10 repetitions for hamstrings, quadriceps, and calf muscles) and 5 minutes jogging, followed by short distance accelerations ( 3 submaximal sprints, progressing to $90 \%$ of their maximal velocity for the shuttle distance $[30+30 \mathrm{~m}])$. 
To evaluate the relative anaerobic power, the running-based anaerobic sprint test (RAST) proposed by Zacharogiannis et al. (2004) was used. The maximum velocity was assessed using a sprint of $30 \mathrm{~m}$ from a start of maximum speed.

Sprint time was measured by means of a dual infrared reflex photoelectric cell system (CEFISE ${ }^{\circledR}$ ). Players began from a standing start, with the front foot $0.5 \mathrm{~m}$ from the first timing gate. Players were allowed two trials, with a two minutes recovery period between.

To measure the explosive power of the lower extremities, players performed the squat jump test (SJ) using a jump mat (Hidrofit, Brasil). According to the procedures proposed by Bosco et al. (1983), players were allowed two trials, with a 1-minute recovery period between each trial.

The "Yo-yo Intermittent Recovery Test Level 1" was conducted according to the methods of Krustrup et al. (2003). This test was designed to evaluate the ability to perform intense exercise repeatedly during prolonged intermittent exercise.

The time allowed for the shuttles was progressively decreased, while the speed was increased. The test was terminated when the subjects failed twice to reach the starting line or the participant felt unable to complete another shuttle at the dictated speed. Distance covered by players was measured and taken to estimate relative maximal oxygen consumption $\left(\mathrm{VO}_{2 \max }\right)$.

\section{Statistical analysis}

Data are presented as means \pm SD. The distribution of each variable was examined using the ShapiroWilk normality test, and homogeneity of variance was verified with a Levene test. Between-group comparisons (pre-, mid-, and post-PHV) were conducted using Kruskal-Wallis test associated with Mann-Whitney test and Bonferroni correction. An alpha level of $p<0.05$ was used to determine statistical significance. Statistical analyses were conducted using the SPSS statistical package for Macintosh (version 21.0, Chicago, IL, USA).

\section{RESULTS}

Thirteen soccer players were identified as being in the Pre-PHV, 33 in the Mild PHV, and 41 in the PostPHV. As expected, participants in the Mild and PostPHV were significantly older, taller and heavier than their counterparts (all $p<0.001$ ). Moreover, participants in the Post-PHV exhibited higher BMI than the other groups $(p<0.001)$ (Table 1$)$.

Table 2 presents the physical performance stratified by maturity groups. Compared to Pre-PHV, participants in the Pos-PHV exhibited better performance for most physical tests (all $p<0.05$ ), except for 30 -meter sprint. Better performance was also found compared to Mild-PHV, except for vertical jump. Regarding Pre and Mild-PHV comparisons, only 30-meter sprint showed between-groups differences $(p<0.05)$.

\section{DISCUSSION}

The primary aim of the present work was to determine whether sprint, jump and endurance performances was affected by maturation in a cohort of young soccer players of an elite club in Brazil. Generally, present results show that locomotor attributes improve with the transition from pre- to post-PHV stages.

Sprinting speed is an essential fitness component for soccer playing (Faude et al.,2012). The results of the present study show that the Mid- PHV 30m sprint was significant differences from Pre-PHV and Post-PHV. Matta et al. (2014) obtained similar results with a group of U-15 soccer players in different stages of maturation, where it was observed significant differences in 30-meter running speed. The scientific literature indicated that physical components in soccer players are related with biological maturation (Vandendriessche et al., 2012). During adolescence maturation stage, the accelerated growth in the length of limbs may contribute to the transitory increase in acceleration and Sprint capabilities from Pre-PHV to Post-PHV. Aditionally, the player drop-out rate and the greater exposure of playing on larger pitch sizes (Murtagh et al., 2018), may constitute alternative explanations for the present results. Therefore, coaches should be aware when soccer players are approaching to attain PHV on account of training loads should be focused on strengthen coordination movement patterns and speed skills (Lloyd \& Oliver, 2012; Lloyd \& Oliver, 2013).

Murtagh et al. (2018) showed that pre-, mid- and post-PHV elite youth soccer players achieved superior acceleration and sprint performance compared to control participants, thus demonstrating that these physiological capabilities may be determinants of elite youth soccer playing status at all stages of maturation, which should be considered as an important factor when identifying talent. Meyers et al. (2017) indicated that it may be important for practitioners to use an integrated approach to developing speed, inclusive of training modes that are focused on enhancing neuromuscular function.

In the vertical jump, the Mid-PHV $(P<0.05)$ and PostPHV $(P<0.01)$, were significantly different from PrePHV. However, from mid-to post-PHV there was a nonsignificant increment on SJ performance. This suggests that the transition from pre-PHV to mid-PHV represents an area of a more marked increase in SJ performance in 
Table 1. Characteristics of the sample according to peak age velocity (PHV).

\begin{tabular}{lcccc}
\hline Variable & $\begin{array}{c}\text { Pre-PHV } \\
(\mathbf{n = 1 3 )}\end{array}$ & $\begin{array}{c}\text { Mid-PHV } \\
(\mathbf{n = 3 3 )}\end{array}$ & $\begin{array}{c}\text { Post-PHV } \\
(\mathbf{n = 4 1 )}\end{array}$ & $\mathbf{p}$ \\
\hline Age $(\mathrm{yrs})$ & $13.15 \pm 0.37$ & $14.45 \pm 0.71^{\mathrm{a}}$ & $17.23 \pm 1.20^{\mathrm{a}, \mathrm{b}}$ & $<0.001$ \\
Height $(\mathrm{cm})$ & $163.08 \pm 6.61$ & $171.48 \pm 7.70^{\mathrm{a}}$ & $178.82 \pm 6.11^{\mathrm{a}, \mathrm{b}}$ & $<0.001$ \\
Body mass $(\mathrm{kg})$ & $55.17 \pm 8.04$ & $63.16 \pm 6.97^{\mathrm{a}}$ & $74.00 \pm 9.19^{\mathrm{a}, \mathrm{b}}$ & $<0.001$ \\
BMI $\left(\mathrm{kg} / \mathrm{m}^{2}\right)$ & $20.61 \pm 2.25$ & $21.54 \pm 2.53$ & $23.24 \pm 2.00^{\mathrm{a}, \mathrm{b}}$ & $<0.001$ \\
\hline
\end{tabular}

${ }^{a}$ Significantly different from Pre-PHV, ${ }^{\text {b }}$ Significantly different from Mid-PHV

Table 2. Physical performance according to peak age velocity (PHV) status in youth soccer players.

\begin{tabular}{lcccc}
\hline Variable & $\begin{array}{c}\text { Pre-PHV } \\
(\mathbf{n = 1 3 )}\end{array}$ & $\begin{array}{c}\text { Mid-PHV } \\
(\mathbf{n = 3 3 )}\end{array}$ & $\begin{array}{c}\text { Post-PHV } \\
(\mathbf{n = 4 1 )}\end{array}$ & $\mathbf{p}$ \\
\hline PHV & $-1.56 \pm 0.32$ & $-0.17 \pm 0.46^{\mathrm{a}}$ & $1.71 \pm 0.77^{\mathrm{a}, \mathrm{b}}$ & $<0.001$ \\
30-meter sprint (s) & $6.24 \pm 0.30$ & $6.73 \pm 0.38^{\mathrm{a}}$ & $6.42 \pm 0.20^{\mathrm{b}}$ & 0.002 \\
Vertical jump (cm) & $32.31 \pm 4.29$ & $36.11 \pm 4.35$ & $38.62 \pm 5.29^{\mathrm{a}}$ & 0.001 \\
VO2max & $51.06 \pm 3.20$ & $53.33 \pm 4.77$ & $60.18 \pm 5.95^{\mathrm{a}, \mathrm{b}}$ & $<0.001$ \\
Yo-Yo test distance (m) & $380.00 \pm 128.37$ & $485.52 \pm 200.77$ & $781.54 \pm 310.08^{\mathrm{a}, \mathrm{b}}$ & $<0.001$ \\
\hline
\end{tabular}

${ }^{a}$ Significantly different from Pre-PHV, ${ }^{b}$ Significantly different from Mid-PHV

youth soccer players. One possible explanation of these results may be related by the fact that maximal gains in muscular strength and power occur, on average, closer to peak weight velocity (Malina et al., 2012). These findings were similar with the ones from (Valentedos-Santos et al., 2012) that support that skeletal age influences the functional performance. Murtagh et al. (2018) indicated that, from a physiological perspective, vertical and horizontal-forward power performance are determinants of elite soccer playing status during the mid-PHV and post-PHV periods, but cannot discriminate between elite youth soccer players and control participants during the pre-PHV period, thus suggesting that jump assessments may be unnecessary for pre-PHV talent identification protocols.

The natural development of aerobic fitness during maturation has been extensively investigated with both several cross-sectional and longitudinal studies (Harrison et al., 2015). Overall, these researches show absolute increases in $\mathrm{VO}_{2 \max }$ of $200 \mathrm{ml} . \mathrm{min}^{-1}$ per year from prior to puberty to approximately 16 years in males, as consequence of an increase in the size of the heart, lungs, and muscles (Harrison et al., 2015). In this study, the result of Yo-yo test distance $(\mathrm{m})$ from Post-PHV was significantly different from Pre-PHV and Mid-PHV $(P<0.01)$. This was in accordance with the results from Deprez et al. (2015) where highest improvement in both subsamples occurred around the timing of PHV (when players moved from pre- to post-PHV). The results were also in accordance with a study of youth Brazilian soccer players (Gouvea et al., 2016) where the U-17 athletes presented superior results in all analysed tests comparing to the U-14 $(p<0.05)$. The results of the present study suggest that through objective physiological assessment, coaches can account maturation status for each player using PHV approach, and prescribe individual aerobic fitness training programs accordingly (Harrison et al., 2015).

Lower rates of fatigue are correlated with conditioning levels in athletes (Silva et al., 2018). An athlete's conditioning can be evaluated by his ability to increase his oxygen consumption during an effort without overloading his anaerobic systems for the production of ATP (Hostrup et al., 2017). It was observed that that only the individuals in the post$\mathrm{PHV}$ group presented $\mathrm{VO}_{2 \max }$ significantly different from the other two groups, suggesting, therefore, that the values of maximum aerobic power were consolidated at the end of the maturation process. This result was in accordance with other studies that show similar results, showing that, when reaching these maximum values of aerobic power, after maturation, these values were sustained, being little altered by the physical training (Malina \& Rogol 2011).

The present study had its limitations that should be acknowledged, such as the Pre-PHV sample size. The experience of players was not controlled, neither their involvement nor other sports practice before soccer. Although the present data should be utilized within the talent development programs, other components like sport specific skills, tactical variables, psychological, and social factors that, unfortunately, have not been analyzed in the present study may be important to success in soccer (Meylan et al., 2010). 
Accordingly to Malina et al. (2015), there is a need to extend research on youth athlete development to the 'cultures' of specific sports, which includes the philosophy of athlete development; sport structure - administrators, coaches, trainers, and other adults; interactions between the structure and athletes; coaching styles, practices and demands; parental involvement and expectations; relationships between athletes and parents, family and peers; an increasingly common view of youth athletes as commodities; an intrusive national and international spotlight; and perhaps other factors.

\section{CONCLUSIONS}

In conclusion, our results provide evidence that the physical and physiological assessments such as vertical jump, $\mathrm{VO}_{2 \text { max }^{\prime}}$ Yo-yo test distance, Fatigue index, and Power (W) performances need to be specific to maturation status in youth soccer players. Thus, coaches and technicians for effective talent identification and selection in soccer needs to take into account physical and physiological maturity to avoid biased selection. Moreover, it is recommended that additional longitudinal research is conducted to a more comprehensively understanding on how PHV influences anthropometric and physical variables.

\section{REFERENCES}

Bosco C, Komi PV, Tihanyi J, Fekete G, Apor P. (1983). Mechanical power test and fiber composition of human leg extensor muscles. Eur J Appl Physiol Occup Physiol. 1983;51(1): 129-135.

Deprez D, Buchheit M, Fransen J, Pion J, Lenoir M, Philippaerts $\mathrm{RM}$, et al. longitudinal study investigating the stability of anthropometry and soccer-specific endurance in pubertal high-level youth soccer players. J Sports Sci Med. 2015;14(2): 418.

Faude $\mathrm{O}$, Koch T, Meyer T. Straight sprinting is the most frequent action in goal situations in professional football. J Sports Sci. 2012;30(7): 625-631.

Gouvea M, Cyrino ES, Ribeiro AS, da Silva DR, Ohara D, ValenteDos-Santos J, et al. Influence of skeletal maturity on size, function and sport-specific technical skills in youth soccer players. Int J Sports Med. 2016;37(06): 464-469.

Harrison CB, Gill ND, Kinugasa T, Kilding AE. Development of aerobic fitness in young team sport athletes. Sports Med. 2015;45(7): 969-983.

Hostrup $M$, Bangsbo J. Limitations in intense exercise performance of athletes-effect of speed endurance training on ion handling and fatigue development. J physiol. 2017;595(9): 2897-2913.

Johnson A, Farooq A, Whiteley R. Skeletal maturation status is more strongly associated with academy selection than birth quarter. Sci Med Football. 2017;1(2): 157-163.

Krustrup $\mathrm{P}$, Mohr M, Amstrup T, Rysgaard T, Johansen J, Steensberg $A$, et al. The yo-yo intermittent recovery test: physiological response, reliability, and validity. Med Sci Sports Exerc, 2003;35(4): 697-705.
Lloyd RS, Oliver JL. The youth physical development model: A new approach to long-term athletic development. Strength Cond J. 2012;34(3): 61-72.

Lloyd RS, Oliver JL. Strength and conditioning for young athletes: science and application. 2nd ed. London: Routledge; 2013.

Malina RM. Biological maturity status of young athletes. In: Malina RM. Young athletes. Biological, psychological and educational perspectives. Champaign: Human Kinetics; 1988.

Malina RM, Coelho-E-Silva MJ, Figueiredo AJ, Carling C, Beunen GP. Interrelationships among invasive and non-invasive indicators of biological maturation in adolescent male soccer players. J Sports Sci. 2012;30(15): 1705-1717.

Malina RM, Rogol AD. Sport training and the growth and pubertal maturation of young athletes. Ped Endocrinol Rev. 2011;9(1): 441-455.

Malina RM, Rogol AD, Cumming SP, Coelho-E-Silva MJ, Figueiredo AJ. Biological maturation of youth athletes: assessment and implications. Br J Sports Med. 2015;49(13): 852-859.

Matta MO, Figueiredo AJ, Garcia ES, Seabra A. Growth, sexual maturation and physical fitness and skills young soccer players: a review. Braz J Soccer Sci. 2014;6(1): 85-99.

Meyers RW, Oliver JL, Hughes MG, Lloyd RS, Cronin JB. Influence of age, maturity, and body size on the spatiotemporal determinants of maximal sprint speed in boys. J Strength Cond Res. 2017;31(4): 1009-1016.

Meylan CM, Cronin J, Hopkins WG, Oliver J. Adjustment of measures of strength and power in youth male athletes differing in body mass and maturation. Pediatr Exerc Sci, 2014;26(1): 41-48.

Meylan CM, Cronin JB, Oliver JL, Hopkins WG, Contreras B. The effect of maturation on adaptations to strength training and detraining in 11-15-year-olds. Scandinavian J Med Sci Sports, 2014;24(3): 156-164.

Meylan C, Cronin J, Oliver J, Hughes M. Talent identification in soccer: The role of maturity status on physical, physiological and technical characteristics. Int J Sports Sci Coaching, 2010;5(4): 571-592.

Mirwald RL, Baxter-Jones AD, Bailey DA, Beunen GP. An assessment of maturity from anthropometric measurements. Med Sci Sports Exerc. 2002;34(4): 689-694.

Murtagh CF, Brownlee TE, O'Boyle A, Morgans R, Drust B, Erskine RM. Importance of Speed and Power in Elite Youth Soccer Depends on Maturation Status. J Strength Cond Research. 2018;32(2): 297-303.

Silva JR, Rumpf MC, Hertzog M, Castagna C, Farooq A, Girard O, Hader K. Acute and Residual Soccer Match-Related Fatigue: A Systematic Review and Meta-analysis. Sports Med. 2018;48(3): 539-583.

Valente-dos-Santos J, Coelho-E-Silva MJ, Simões F, Figueiredo AJ, Leite $N$, Elferink-Gemser, MT, et al. Modeling developmental changes in functional capacities and soccerspecific skills in male players aged $11-17$ years. Pediatr Exerc Sci, 2012;24(4): 603-621.

Vandendriessche JB, Vaeyens R, Vandorpe B, Lenoir M, Lefevre J, Philippaerts RM. Biological maturation, morphology, fitness, and motor coordination as part of a selection strategy in the search for international youth soccer players (age 15-16 years). J Sports Sci, 2012;30(15): 1695-1703.

Zacharogiannis E, Paradisis G, Tziortzis S. An evaluation of tests of anaerobic power and capacity. Med Sci Sports Exerc. 2004;36(5): 116. 